\title{
Impact of Anomalous Northward Oceanic Heat Transport on Global Climate in a Slab Ocean Setting
}

\author{
BLANDINE L'HÉvÉDER AND FRANCIS CODRON \\ Laboratoire de Météorologie Dynamique, L'Institut Pierre-Simon Laplace, Centre National de la Recherche Scientifiques, \\ Ecole Normale Supérieure, and Université Pierre et Marie Curie, Paris, France \\ MiCHAEL GHIL \\ Atmospheric and Oceanic Sciences Department, and Institute of Geophysics and Planetary Physics, University of \\ California, Los Angeles, Los Angeles, California
}

(Manuscript received 28 May 2014, in final form 15 December 2014)

\begin{abstract}
This paper explores the impact of anomalous northward oceanic heat transport on global climate in a slab ocean setting. To that end, the GCM LMDZ5A of the Laboratoire de Météorologie Dynamique is coupled to a slab ocean, with realistic zonal asymmetries and seasonal cycle. Two simulations with different anomalous surface heating are imposed: 1) uniform heating over the North Atlantic basin and 2) concentrated heating in the Gulf Stream region, with a compensating uniform cooling in the Southern Ocean in both cases. The magnitudes of the heating and of the implied northward interhemispheric heat transport are within the range of current natural variability. Both simulations show global effects that are particularly strong in the tropics, with a northward shift of the intertropical convergence zone (ITCZ) toward the heating anomalies. This shift is accompanied by a northward shift of the storm tracks in both hemispheres. From the comparison between the two simulations with different anomalous surface heating in the North Atlantic, it emerges that the global climate response is nearly insensitive to the spatial distribution of the heating. The cloud response acts as a large positive feedback on the oceanic forcing, mainly because of the low-cloud-induced shortwave anomalies in the extratropics. While previous literature has speculated that the extratropical $Q$ flux may impact the tropics by the way of the transient eddy fluxes, it is explicitly demonstrated here. In the midlatitudes, the authors find a systematic northward shift of the jets, as well as of the associated Ferrel cells, storm tracks, and precipitation bands.
\end{abstract}

\section{Introduction}

Considerable attention has been directed over the last decade to the effects of extratropical thermal forcing on the global atmosphere, including on tropical climate (Broccoli et al. 2006; Kang et al. 2008; Frierson and Hwang 2012; Donohoe et al. 2013; Mahajan et al. 2013). When thermal forcing is applied in middle or even high latitudes, a shift in the intertropical convergence zone (ITCZ) occurs, along with changes in the trade winds and an asymmetric response of the Hadley circulation.

\footnotetext{
Corresponding author address: Blandine L'Hévéder, Laboratoire de Météorologie Dynamique, Université Paris VI, Tour 45553 e étage, Case postale 99, 4 place Jussieu, F 75252 Paris CEDEX 05 , France.

E-mail: blandine.lheveder@lmd.jussieu.fr
}

Different mechanisms have been proposed to explain the meridional propagation of the extratropical circulation changes into the tropics and the tropical response amplification. These mechanisms include a wind-evaporationsea surface temperature (SST) (WES) feedback (Chiang and Bitz 2005) or diffusion by transient and stationary eddies (Cheng et al. 2007) for the meridional propagation, changes in cloud cover (Kang et al. 2008), and also WES feedback (Mahajan et al. 2011) for the tropical response amplification.

The extratropical thermal forcing may be radiativethat is, albedo changes due to land, sea ice or cloud cover, or aerosols-or due to a change in the ocean heat transport. The first studies that addressed these issues (Chiang and Bitz 2005; Broccoli et al. 2006) were modeling the Last Glacial Maximum (LGM) and the global impact of the radiative forcing related to the large 
changes associated with land and sea ice cover, resulting in an hemisphere-wide cooling and a southward shift in the ITCZ over all tropical ocean basins. Recent studies (Marshall et al. 2014; Fučkar et al. 2013; Frierson et al. 2013) have also highlighted the role of the ocean-that is, cross-equatorial oceanic meridional heat transport (OMHT) - in displacing the mean ITCZ position toward the hemisphere that is being heated. This effect is also seen in so-called hosing experiments, in which a large freshwater flux added to the North Atlantic brings about an abrupt collapse of the Atlantic meridional overturning circulation (AMOC) and leads to Northern Hemisphere cooling, a southward displacement of the ITCZ, and various impacts outside the Atlantic Ocean (Zhang and Delworth 2005; Cheng et al. 2007). Through atmospheric and oceanic teleconnections, such a freshwater input in the North Atlantic may also influence the North Pacific climate (Zhang and Delworth 2005, 2007; Okumura et al. 2009) or the meridional position of the Southern Hemisphere jet (Ceppi et al. 2013). Finally, several studies of the impact of aerosols (Chen and Ramaswamy 1996; Yoshimori and Broccoli 2008; Ming and Ramaswamy 2009; Mahajan et al. 2013) have shown that the hemispherically asymmetric aerosol forcing result in a response similar to hosing experiments or LGM studies, but with a magnitude of cross-equatorial heat transport closer to natural present climate variability.

Cloud radiative feedbacks - and more particularly those of extratropical low clouds-have also been shown to play a crucial role in determining the ITCZ response to extratropical forcings (Kang et al. 2008, 2009; Ming and Ramaswamy 2009; Zhang et al. 2010; Frierson and Hwang 2012; Hwang and Frierson 2013; Seo et al. 2014). They may also modulate the propagation of the thermal forcing from the tropics to the opposite hemisphere (Ceppi et al. 2013). Kang et al. (2008, 2009) first highlighted the crucial role of clouds in an idealized aquaplanet setting, and Zhang et al. (2010) further analyzed extensively in a more realistic configuration. Recently, Seo et al. (2014) attributed the larger efficiency of extratropical thermal forcing versus tropical forcing in shifting the ITCZ to the radiative effects of extratropical low clouds. In contrast, Voigt et al. (2014) found in their setup that the ITCZ shifts arose from tropical cloud changes, with extratropical cloud changes playing a secondary role. The relative importance of tropical versus extratropical cloud changes presumably depends on how the ITCZ shift is triggered and whether the reference simulation is symmetric about the equator as for aquaplanets or is characterized by strong extratropical cloud differences between the Northern and Southern Hemispheres as for realistic model configurations. Finally, Donohoe et al. (2014) went further and demonstrated how the ITCZ shift itself could feed back on the hemispheric asymmetry of energy input into the atmosphere and the atmospheric heat transport across the equator.

Most of these studies examined rather extreme cases of anomalous forcing, either in terms of forcing amplitude—such as LGM climate, AMOC collapse or strong heat flux anomalies-or in terms of geometry, such as an idealized aquaplanet (Kang et al. 2008, 2009, 2014; Seo et al. 2014). For example, in Broccoli et al. (2006), the heat flux anomaly of $10 \mathrm{~W} \mathrm{~m}^{-2}$ imposed to the slab ocean poleward of $40^{\circ}$ corresponds to an OMHT of $0.85 \mathrm{PW}$. Or, in idealized aquaplanet simulations, Kang et al. $(2008,2009)$ prescribe a large OMHT anomaly of $-3.5 \mathrm{PW}$. The induced cross-equatorial OMHT change of $-0.30 \mathrm{PW}$ in the Atlantic Ocean in hosing experiments seems less extreme (Zhang and Delworth 2005; Cheng et al. 2007), but is still comparable to the full observed value of $0.4 \pm 0.1 \mathrm{PW}$ (Marshall et al. 2014).

In our study, we concentrate on the global climate impacts of northward anomalies in Atlantic OMHT that could be associated with interannual to decadal variability of the AMOC. We therefore use a smaller amplitude of less than $0.1 \mathrm{PW}$ (see section 2), with a realworld geography and a seasonal cycle. The model used is an IPCC-class atmospheric GCM coupled to a slab ocean, in which anomalous heat fluxes can be prescribed.

The OMHT takes place in large part in its surface branch in western boundary currents such as the Gulf Stream. A number of studies have shown that the sharp SST gradients associated with the Gulf Stream locally strongly affect the atmosphere (Feliks et al. 2007; Minobe et al. 2008; Brachet et al. 2012). Moreover, it was suggested that SST fronts may also have remote impacts, notably through their influence on developing baroclinic waves (Willison et al. 2013), or just because the presence of SST fronts tends to increase surface heat fluxes (Brachet et al. 2012). To test for these effects, our sensitivity experiments were designed with two extreme cases of the spatial distribution of the prescribed ocean heat flux anomalies in the North Atlantic basin. In the North Atlantic (NA) experiment, the heating is uniformly distributed between $30^{\circ}$ and $60^{\circ} \mathrm{N}$. In contrast, the same heating is concentrated in the narrow Gulf Stream region in the Gulf Stream (GS) experiment, as if all the increased OMHT was released to the atmosphere there. The idealized ocean heat flux anomalies in the North Atlantic basin applied in the two experiments are shown in Fig. 1.

This experimental design of the simulations is described in more details in section 2 . The resulting impacts on the global climate are described in section 3 . Changes in the energy budget and meridional transport are discussed in section 4, with a special focus on 
(a) NA

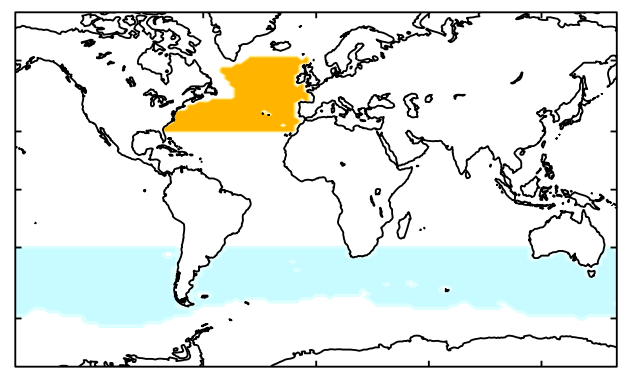

(b) GS

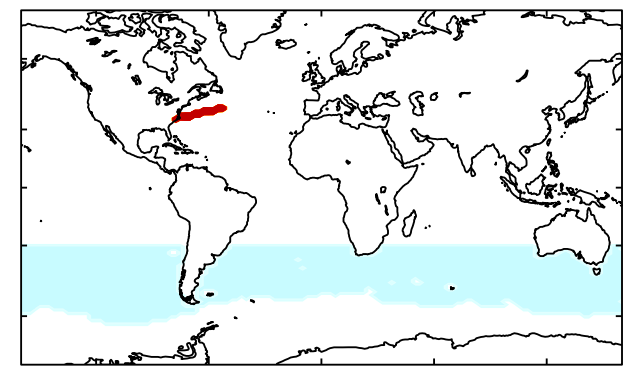

FIG. 1. Distribution of anomalous $Q$ fluxes: (a) uniformly enhanced over the North Atlantic basin (NA experiment); and (b) enhanced over the Gulf Stream region (GS experiment). The amplitude of the $Q$-flux anomalies is $6 \mathrm{~W} \mathrm{~m}^{-2}$ in the NA experiment and roughly $150 \mathrm{~W} \mathrm{~m}^{-2}$ in the GS experiment in the North Atlantic Ocean vs $1 \mathrm{~W} \mathrm{~m}^{-2}$ in the Southern Hemisphere's midlatitudes.

radiative feedbacks in section 5. Discussion of the results and conclusions are given in section 6.

\section{Experimental setup}

The atmospheric model employed in this study is the GCM LMDZ5A of the Laboratoire de Météorologie Dynamique (Hourdin et al. 2013). LMDZ5A is the atmospheric component of the IPSL-CM5A climate model used by L'Institut Pierre-Simon Laplace (IPSL) CMIP5 runs; where 5 represents the model generation, $\mathrm{Z}$ indicates zooming capability [as used for instance by Brachet et al. (2012)], and A indicates standard physical parameterizations. This GCM has a horizontal resolution of $1.25^{\circ}$ latitude by $2.5^{\circ}$ longitude and 39 vertical levels. The model is run here in a realistic configuration, with real-world land distribution and topography, at the indicated resolution. Greenhouse gas and ozone concentrations representative of the $2000 \mathrm{~s}$ are used, and no aerosols are added.

The atmosphere is coupled to a motionless slab ocean of 50-m depth, with prescribed sea ice cover. The use of the slab ocean as the lower boundary ensures that the surface energy budget is closed, except for sea ice formation and melting. The heat transport by the ocean circulation is accounted for by adding a seasonal heat flux $Q$ to the surface heat fluxes. This heat flux is referred to hereafter as the $Q$ flux, and it is calculated to maintain a seasonal cycle of ocean temperatures as close as possible to present-day conditions. The imposed $Q$ flux is derived from a 30-yr uncoupled simulation performed with the same LMDZ5A configuration, using fixed AMIP climatological SST and sea ice concentration (SIC). The climatology of the imposed $Q$ flux compares well with $Q$ flux derived from observed climatology-for example, from the Comprehensive Ocean-Atmosphere Data Set (COADS) and the bulk formulas of Isemer and
Hasse (1987). Then, the LMDZ slab model is run for 30 years with the imposed $Q$ flux, to provide an equilibrated initial state for the three experiments.

A control experiment was performed by running the LMDZ 50-m slab model from the initial state for 120 years. The climatology is computed as an averaged over these 120 years. The SST seasonal cycle is very close to the AMIP one, as expected by construction. The precipitation climatology has a realistic distribution in terms of spatial pattern and precipitation amounts, compared to the climatology from the Global Precipitation Climatology Project (GPCP) over 1979-2010 (Adler et al. 2003).

The zonal-mean distribution of the control experiment's precipitation climatology is plotted in Fig. 2a (thick black curve), as well as the zonal-mean climatology of GPCP (thin black curve). In the control simulation, the positions of the maxima in the tropics and at midlatitudes are correct. The maximum of $6 \mathrm{~mm}^{2} \mathrm{day}^{-1}$ at $7^{\circ} \mathrm{N}$ corresponds to the ITCZ position. The tropical Southern Hemisphere peak, which marks the ITCZ's position in austral summer, is slightly overestimated, whereas the midlatitude values are well reproduced. The amplitude error between our simulation and the GPCP observations is in the same range as the errors between the different observation datasets (not shown).

We now describe in greater detail the two perturbed experiments, which were designed to study the impact of anomalous heating in the North Atlantic that would be caused by an excess northward OMHT, as well as the possible role of the spatial distribution of that heating.

\section{a. Heat transport magnitude}

In both experiments, the same northward crossequatorial OMHT of $0.08 \mathrm{PW}$ is imposed. This value was chosen as an estimate of typical amplitude of present-day decadal variability resulting from natural fluctuation of the AMOC. 
(a) precipitation

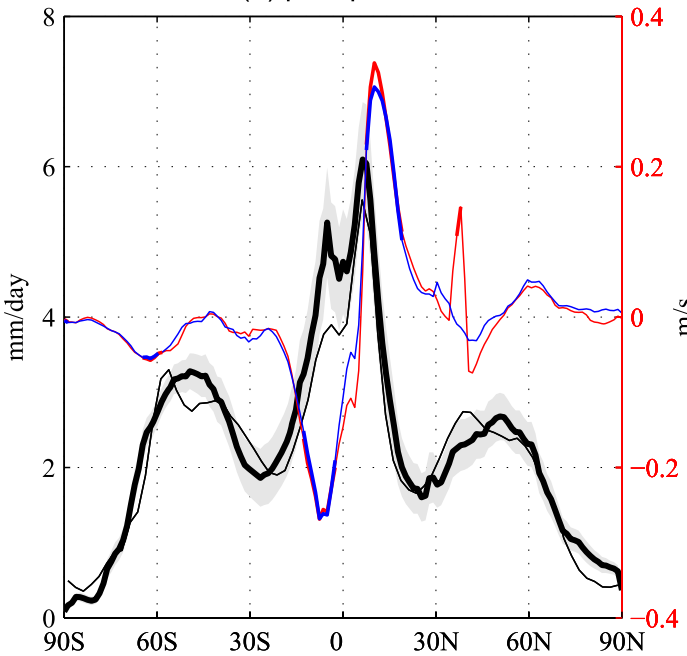

(b) U850

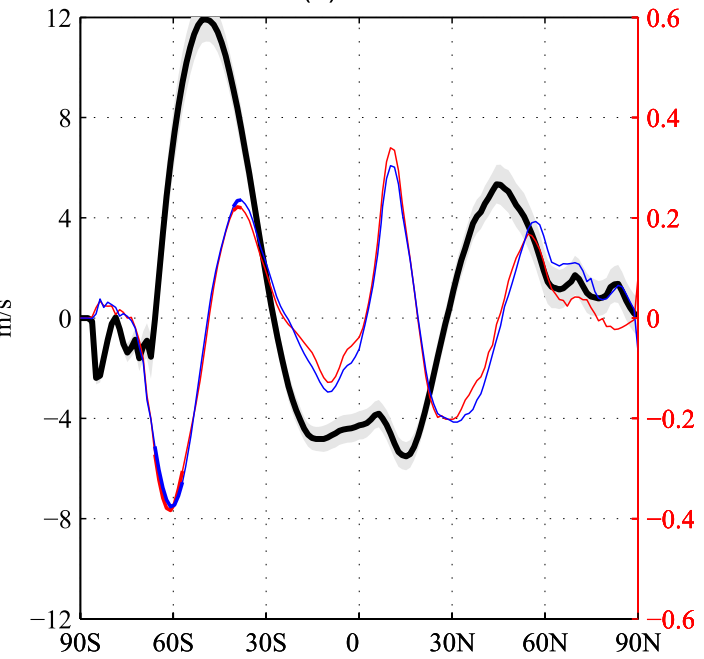

FIG. 2. Zonal-mean climatology (thick black curves, values on left ordinate) and anomalies in the two experiments: blue curves for NA and red curves for GS, with values on the right ordinate. (a) Precipitation $\left(\mathrm{mm} \mathrm{day}^{-1}\right)$, and (b) zonal wind at $850 \mathrm{hPa}\left(\mathrm{m} \mathrm{s}^{-1}\right)$. The gray-shaded strip represents the error bar for the zonal-mean climatology ( \pm 1 std dev of the interannual model's free variability), and the thin black line the precipitation observations: zonalmean climatology of GPCP. For the anomalies, differences that are statistically significant at the $95 \%$ confidence level, according to a two-sided $t$ test, are drawn as a thick line.

Baringer et al. (2013) provided a review study comparing observed time series of OMHT in the Atlantic at $41^{\circ} \mathrm{N}, 26^{\circ} \mathrm{N}$, and $35^{\circ} \mathrm{S}$ to estimates from the ECCO Production OGCM (ECCO-PROD) and the Simple Ocean Data Assimilation (SODA) models. The interannual variability of the OMHT, characterized by its standard deviation in both observations and assimilating models, ranges from 0.1 to $0.2 \mathrm{PW}$, with a mean observed OMHT ranging from $0.5 \mathrm{PW}$ in midlatitudes to $1.26 \mathrm{PW}$ at $26^{\circ} \mathrm{N}$.

Using the SODA analysis, Zheng and Giese (2009) evaluated the interannual variability of OMHT in the Atlantic over a longer period 1958-2004. They found OMHT standard deviation varying between $0.04 \mathrm{PW}$ in high latitudes to $0.17 \mathrm{PW}$ in the tropics with a mean value of $0.1 \mathrm{PW}$ in the Atlantic Ocean. Using a $450-\mathrm{yr}$ preindustrial simulation performed with the GFDL CM2.1 coupled model, Donohoe et al. (2014) estimated that the OMHT anomaly associated with the AMOC anomaly was of order 0.1 PW. Note that all of these values are for yearto-year variability and should be lowered for longer time scales at which the climate system has more time to adjust.

\section{b. Prescribed heat flux anomalies}

In the first sensitivity simulation, called NA, the prescribed $Q$-flux anomalies are homogeneously distributed over the entire North Atlantic region, between $30^{\circ}$ and $60^{\circ} \mathrm{N}$, except over grid points were seasonal sea ice is present (Fig. 1a). In the second GS simulation, the $Q$-flux anomalies are concentrated in a small region along the Gulf Stream (Fig. 1b), overlapping the local ocean-atmosphere heat flux maximum. Following Brachet et al. (2012), these anomalies are centered at $39.5^{\circ} \mathrm{N}, 65^{\circ} \mathrm{W}$, with a $5^{\circ}$ crossfront width, a $25^{\circ}$ alongfront length, and a spatial pattern given by

$$
Q(\xi, \eta)=A \cos \xi \cos \eta .
$$

Here $(\xi, \eta)$ are the alongfront and cross-front coordinates, rotated counterclockwise by $12^{\circ}$ with respect to the usual east-west and north-south coordinates $(x, y)$. The magnitude of the local $Q$-flux anomalies reaches $A=200 \mathrm{~W} \mathrm{~m}^{-2}$ in the GS simulation, but is constant at $6 \mathrm{~W} \mathrm{~m}^{-2}$ in the NA one.

To conserve the global energy budget, the same ocean energy amount was removed from the midlatitudes of the Southern Hemisphere, between $30^{\circ}$ and $60^{\circ} \mathrm{S}$. The detailed spatial distribution of the negative corresponding $Q$-flux anomaly forcing is shown in Figs. 1a,b; in both perturbed experiments, it only includes grid points that are free of ice year-round. The resulting uniform magnitude of the flux is of roughly $A=1 \mathrm{~W} \mathrm{~m}^{-2}$. The anomalous $Q$-flux dipole between the two hemispheres (cf. Fig. 1) may thus represent an idealized strengthening of the AMOC, with a homogeneous cooling in the Southern Ocean and two distinct heating patterns in the North Atlantic. The associated magnitude of the northward OMHT in the Atlantic is of $0.08 \mathrm{PW}$. Note that there is no $Q$-flux anomaly anywhere in the tropics, that is, not even within the entire $30^{\circ} \mathrm{S}-30^{\circ} \mathrm{N}$ band.

The length of both perturbed experiments is 125 years, starting from the same initial state as the control 
(a) GS-CTRL

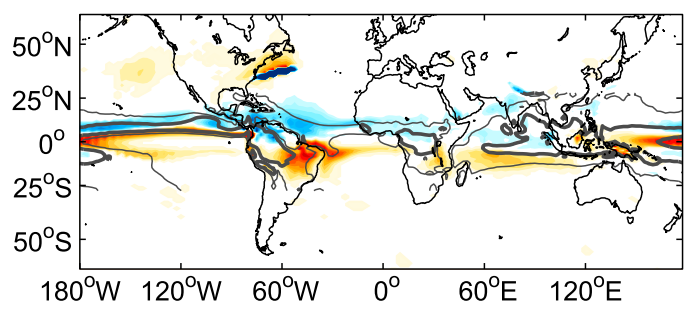

(b) NA-CTRL

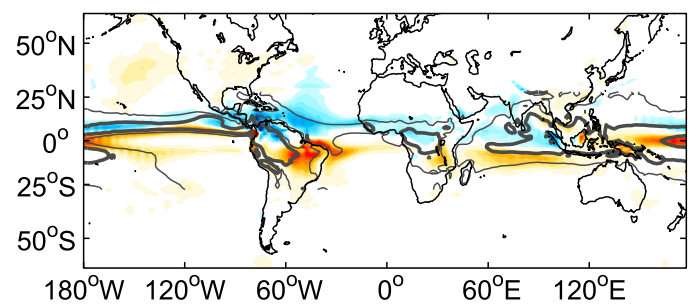

(c) GS-NA
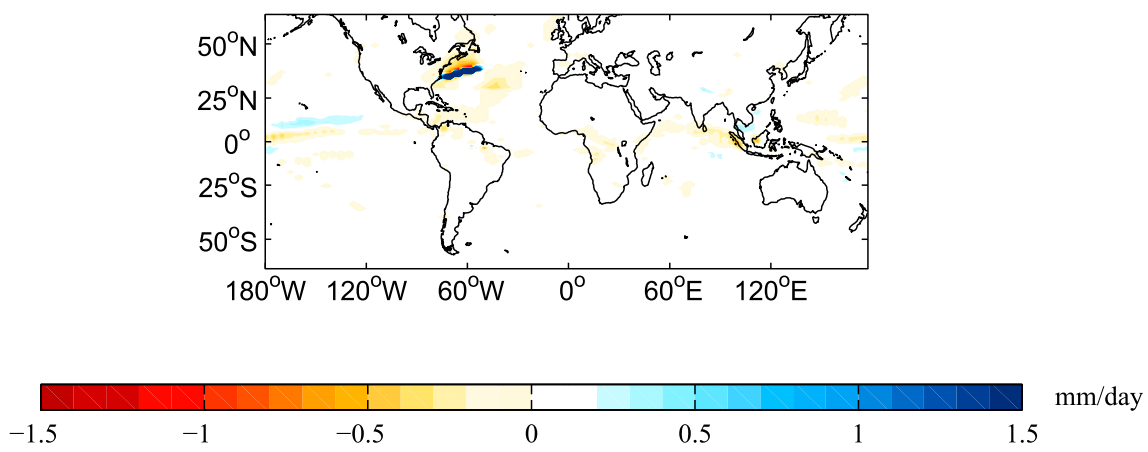

FIG. 3. Mean precipitation differences between (a) the GS and control experiments, (b) the NA and control experiments, and (c) the GS and NA experiments. Differences that are statistically significant at the $95 \%$ confidence level, according to a two-sided $t$ test, are shaded $\left(\mathrm{mm} \mathrm{day}^{-1}\right)$. Gray contours represent climatological precipitation contours (light solid line: $3 \mathrm{~mm}_{\text {day }}{ }^{-1}$; thick solid line: $6 \mathrm{~mm}$ day $^{-1}$ ).

experiment. The last 120 -yr mean is then used to compute the anomaly between the perturbed and control simulations, discarding the first 5 years as spinup ( 5 years are sufficient to equilibrate with a 50-m depth slab ocean). All quantities shown in this paper are annual means; 120-yr means over separate seasons were also analyzed and they yield the same qualitative picture, with some variations resulting from the differences in the seasonal mean states (not shown).

\section{Impact on global climate}

As stated in the introduction, the amplitude of the imposed $Q$-flux perturbations here is smaller than in previous studies (e.g., Broccoli et al. 2006; Chiang and Bitz 2005; Kang et al. 2008; Okumura et al. 2009; Frierson and Hwang 2012). Nonetheless, we obtain a significant climate response at the global scale, as shown in Figs. 3a,b for precipitation: a meridional dipole of anomalies and a northward shift of the precipitation maximum emerge in the tropics at all longitudes.

A second interesting result is that the global response is very similar in the GS and NA simulations. Figure 3c illustrates this result quite well: the global response to a midlatitude thermal forcing is nearly independent of the spatial distribution inside the North Atlantic basin.

\section{a. Similarity of the response in $G S$ and $N A$ experiments}

The remote global response to the anomalous heating in North Atlantic is very similar in NA and GS experiments. It is evident in a number of anomaly fields such as the precipitation (Fig. 3) and TOA radiation (Fig. 9), as well as on the zonal averages of precipitation, zonal wind at $850 \mathrm{hPa}$ (Fig. 2), implied atmospheric transport (Fig. 6), and TOA radiation (Fig. 10).

The only differences between the NA and GS experiments responses are local, just above the $Q$-flux forcing (Figs. 3c, 9b). Indeed, in the GS simulation, the local response to the strong $Q$-flux anomaly concentrated in the Gulf Stream takes the form of an intense and narrow band of increased precipitation (up to $8 \mathrm{~mm} \mathrm{day}^{-1}$ ), associated with enhanced convection, an increase in highcloud amount, and a strong decrease of low-cloud cover, in agreement with previous studies (Minobe et al. 2008; Brachet et al. 2012).

The global remote response of increased $Q$ flux therefore seems independent of the spatial distribution of the heating inside North Atlantic basin, even though there are strong local impacts. This paper concentrates on the global impacts, so hereafter the analysis and discussion will be limited to the NA simulation. 


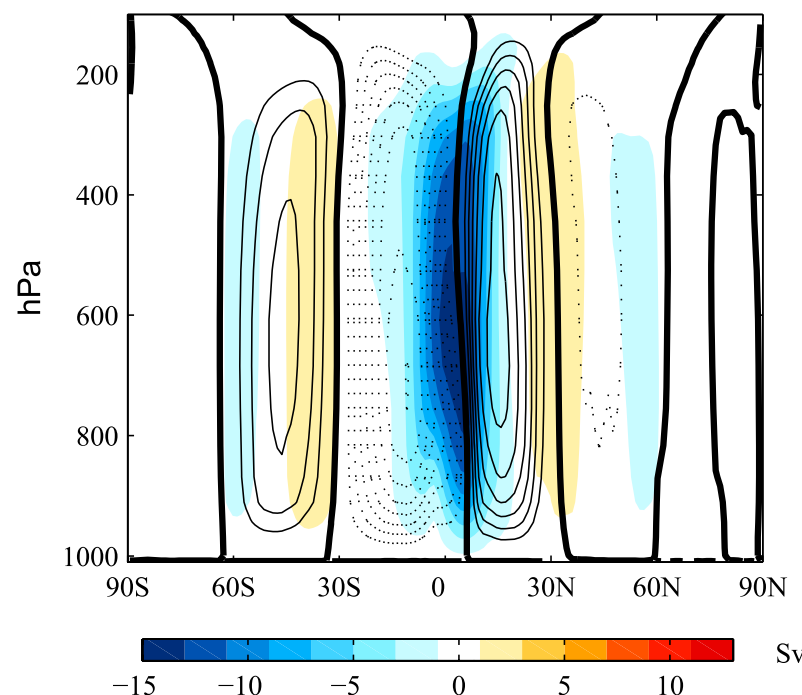

FIG. 4. Mean meridional streamfunction in the control experiment (light solid contours every $10 \mathrm{~Sv}$, zero contour thick solid), and its anomaly between the NA and control experiments (shading in Sv, see color bar).

\section{b. Precipitation changes}

Changes in interhemispheric thermal gradients are known to shift the ITCZ toward the warmer hemisphere (e.g., Broccoli et al. 2006; Kang et al. 2008, 2009; Frierson and Hwang 2012; Marshall et al. 2014). In our perturbed experiments, the tropical precipitation maximum is likewise shifted toward the heated Northern Hemisphere (Figs. 3a,b). This shift occurs over all longitudes, and over land as well as ocean.

In our realistic setting, the precipitation response is, however, not simply a shift of a single ITCZ peak, as in idealized experiments performed with an aquaplanet and no seasonal cycle (Kang et al. 2008, 2009; Seo et al. 2014). Comparing the anomalies (colors) with the mean precipitation (contour lines) in Figs. 3a,b, as well as inspecting the zonally averaged picture in Fig. 2a, one detects a northward shift of the ITCZ peak being accompanied by a general weakening of precipitation in the Southern Hemisphere and a strengthening in the northern one. The order of magnitude of the anomalies is about $5 \%$ of the climatological maximum.

Qualitatively similar precipitation changes are observed throughout the year, with some seasonal variations (not shown): the ITCZ shift is smaller and the precipitation peak moves less in boreal summer, when the climatological ITCZ peak is farther from the equator, as found by Donohoe et al. (2013).

\section{c. Links with the cross-equatorial heat transport}

The usual explanation for the ITCZ shift in response to an interhemispheric heating gradient involves

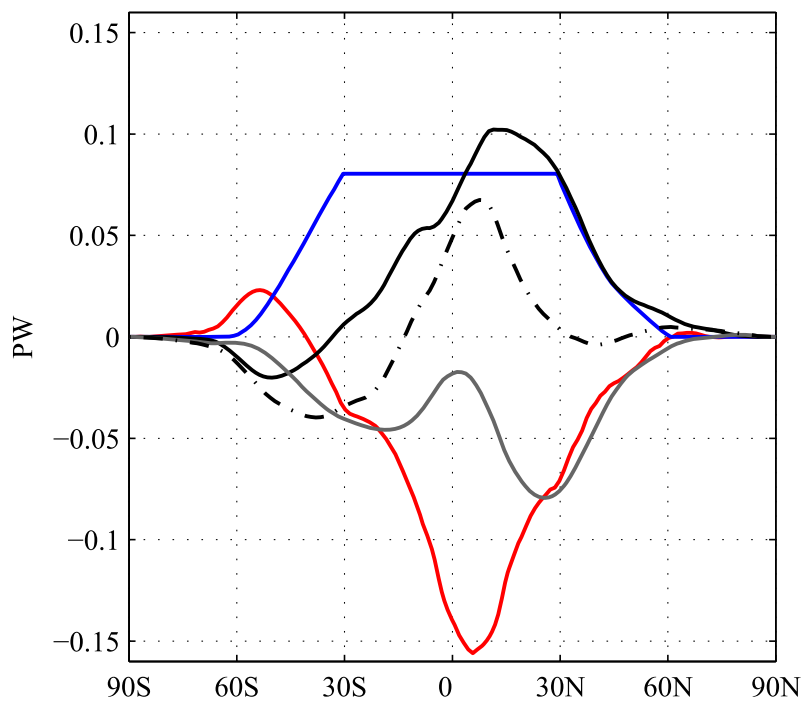

FIG. 5. Anomalous zonally averaged energy transport in the NA simulation: imposed anomalous oceanic transport $F_{o}$ (blue), atmospheric transport change $F_{a}$ (red), implied meridional transport corresponding to the change in TOA cloud radiative effect (black), clear-sky radiation (gray), and total TOA radiation (black dashed dotted). TOA outgoing values are negative.

a compensating energy transport by the atmosphere; this transport is accomplished in the tropics by the crossequatorial Hadley cell. Such a response is evident in Fig. 4, which shows the mean meridional atmospheric overturning streamfunction of the control run, together with its anomaly in the NA simulation. The asymmetry in Hadley cell strength is enhanced: the northward nearsurface transport in the cross-equatorial Hadley cell is increased by $12 \mathrm{~Sv}\left(\mathrm{~Sv} ; 1 \mathrm{~Sv} \equiv 10^{6} \mathrm{~m}^{3} \mathrm{~s}^{-1}\right)$ in the NA case, and the boundary between the Hadley cells shifts northward by about $0.7^{\circ}$, as we shall see below. This anomalous circulation will transport total atmospheric energy southward, while the moisture transport is northward.

The ratio of the ITCZ shift to the atmospheric heat transport across the equator $\left(\mathrm{AHT}_{\mathrm{eq}}\right)$ is a useful indicator for this mechanism, and it has been used in Donohoe et al. (2013) to perform model intercomparisons. The mean position of the ITCZ is evaluated using the precipitation centroid $P_{\text {cent }}$, defined by Frierson and Hwang (2012) as the median of the distribution of zonal-mean precipitation from $20^{\circ} \mathrm{S}$ to $20^{\circ} \mathrm{N}$. The zonal-mean precipitation is interpolated here to a $0.1^{\circ}$ grid over the tropics to allow us to estimate the $P_{\text {cent }}$ shift in increments smaller than the GCM's grid spacing.

In both perturbed experiments, $P_{\text {cent }}$ shifts by $0.7^{\circ}$ northward from its $1^{\circ} \mathrm{N}$ mean position in the control experiment. At the same time, the northward meridional heat transport in the atmosphere decreases by $0.15 \mathrm{PW}$ in both perturbed experiments, as seen in Fig. 5, 
which gives a ratio of $-4.6^{\circ} \mathrm{PW}^{-1}$ for the shift of the ITCZ $P_{\text {cent }}$ with a change in $\mathrm{AHT}_{\text {eq. }}$.

This value is consistent with the multimodel and multiexperiment scatterplot of Fig. 10 in Donohoe et al. (2013). Frierson and Wang (2012) provided another estimation of this ratio by comparing $2 \times \mathrm{CO}_{2}$ experiments with different slab ocean models. In their Fig. 3, the regression of $P_{\text {cent }}$ with respect to $\mathrm{AHT}_{\text {eq }}$ gives about $-6^{\circ} \mathrm{PW}^{-1}$, with a shift of $1.5^{\circ}$ for $-0.25 \mathrm{PW}$. Mahajan et al. (2013) also recently estimated that the ITCZ centroid shifts at a rate of $4^{\circ} \mathrm{PW}^{-1}$ in CAM4, albeit when the cross-equatorial transport is induced by black carbon aerosols. Thus the ratio of $-4.6^{\circ} \mathrm{PW}^{-1}$ found in our simulations falls within this range from $-6^{\circ}$ to $-3^{\circ} \mathrm{PW}^{-1}$ reported in the literature.

\section{d. Midlatitude response}

In addition to the main changes in the tropical precipitation, the zonal-mean picture of Fig. 2a also shows a northward shift of the secondary precipitation maxima in the midlatitudes of both hemispheres, with a dipole centered around $50^{\circ}$ in each hemisphere. This shift in precipitation corresponds to a northward shift of the jets and storm tracks; the latter shift is clearly seen in Fig. 2b, where the zonal-mean anomalies of the zonal wind at $850 \mathrm{hPa}$ is plotted. The Ferrel cells are also slightly modified (cf. Fig. 4): the Northern Hemisphere one is shifted northward and the Southern Hemisphere one is strengthened.

\section{Energy transport changes}

In response to the extratropical thermal forcing, the boundary between the usual two Hadley cells shifts northward, and an anomalous cross-equatorial cell appears in Fig. 4. These changes suggest that the imposed northward OMHT — as implied by the similar magnitude of the spatially integrated surface heat fluxes imposed in our NA and GS simulations-is partially compensated by a southward energy transport in the atmosphere. To quantify the repartition of the changes between the energy transports in the atmosphere and oceans, and the energy inputs at the top of the atmosphere, we now compare the energy budgets in the control experiment and the two anomalously forced simulations.

In zonal and time mean, the TOA net radiation is balanced by the divergence of the atmospheric and oceanic heat transport:

$$
\nabla \cdot \mathbf{F}_{a}+\nabla \cdot \mathbf{F}_{o}=\text { TOA }
$$

Here TOA is the zonal- and time-mean net incoming radiation at top of the atmosphere, $\mathbf{F}_{o}$ is the meridional heat transport in the ocean-which can be deduced in our experiments from the imposed $Q$ flux-and $\mathbf{F}_{a}$ is the vertically integrated moist static energy transport in the atmosphere. At latitude $\phi, F_{a}$ is given by

$$
F_{a}(\phi)=\frac{-2 \pi a \cos \phi}{g} \int_{p_{s}}^{0}[\overline{v \mathrm{MSE}}] d p,
$$

where $a$ is the radius of the earth, $g$ is the acceleration of gravity, $v$ is the meridional velocity, and MSE is the moist static energy, while the overbar denotes the time average and square brackets denote the zonal average, according to the classical conventions of Lorenz (1967). The MSE, in turn, is the sum of the sensible, latent, and potential energies,

$$
\mathrm{MSE}=c_{p} T+L q+g z
$$

where $c_{p}$ is the specific heat at constant pressure, $T$ is the temperature, $L$ is the latent heat, $q$ is the specific humidity, and $z$ is the geopotential height.

Figure 5 shows the changes in the meridional energy transport between the NA and control experiments. In this figure, the atmospheric transport $F_{a}$ is diagnosed by the dynamic calculation detailed in Eq. (3), and the anomalous oceanic transport $F_{o}$ is computed from the spatial integration of the imposed $Q$-flux anomaly

$$
F_{o}(\phi)=\int_{-\pi / 2}^{\phi} 2 \pi a^{2} \cos \phi[Q] d \phi
$$

where $a$ is the radius of the earth, $Q$ is the $Q$-flux anomaly, and square brackets denote the zonal average.

In the NA experiment, the imposed northward oceanic energy transport anomaly (blue) has a north-south symmetry in zonal mean, with a plateau of $0.08 \mathrm{PW}$ between $30^{\circ} \mathrm{S}$ and $30^{\circ} \mathrm{N}$. The response of the atmospheric MSE transport anomaly (red) is mostly to the south of the anomalous forcing, and it reaches a maximum of about $0.15 \mathrm{PW}$ at the boundary between the Hadley cells that is situated around $7^{\circ} \mathrm{N}$.

Thus, the atmospheric MSE transport overcompensates the oceanic energy transport anomaly in the deep tropics. An increase of $0.08 \mathrm{PW}$ of the implied northward ocean heat transport $F_{o}$ leads to a double amplitude change $(0.15 \mathrm{PW})$ of the atmospheric southward transport $F_{a}$ at the equator.

Differences between the atmospheric and oceanic transports, and especially the overcompensation in the tropics, must be due to TOA fluxes. The meridional transport implied by TOA clear-sky and cloudy-sky radiation budgets are estimated from the spatially integrated TOA radiative fluxes, using the same Eq. (5) as for $F_{o}$, only adding a time average. The computation of 
the TOA radiation budgets was used to check that the steady-state energy balance defined in Eq. (2) was well satisfied in our simulations. The meridional transport implied by TOA fluxes are plotted in Fig. 5, separately for the clear-sky component (CS; gray) and the cloud radiative effect (CRE; black). The two components tend to oppose each other, with the CS radiation canceling the ocean transport, and the CRE providing a positive feedback to the ocean transport. The compensation is strong in the midlatitudes, and less so in the tropics. This TOA response is studied in greater detail in section 5 .

To distinguish the roles of different dynamical processes, the atmospheric MSE transport anomaly is decomposed as follows:

$$
F_{a}(\phi)=\frac{-2 \pi a \cos \phi}{g} \int_{p_{s}}^{0} \underbrace{[\bar{v}][\overline{\mathrm{MSE}}]}_{\mathrm{MMC}}+\underbrace{\left[\overline{\bar{v}^{\prime} \mathrm{MSE}^{\prime}}\right]}_{\mathrm{TRS}}+\underbrace{\left[\overline{v^{*} \mathrm{MSE}^{*}}\right]}_{\mathrm{STN}} d p
$$

Here the overbar denotes monthly means, square brackets denote the zonal average as before, the prime denotes the departure from the time average, and the asterisk denotes the departure from the zonal average, as in Lorenz (1967). The zonal-mean energy flux is an online diagnostic, calculated every time step (10 min) and saved as monthly mean. The first term in Eq. (6) is the energy transport associated with the mean meridional circulation (MMC). The second term represents the transport by transient eddies (TRS), and the last term is the contribution by the stationary waves (STN).

The total atmospheric MSE transport and its decomposition into the MMC, TRS, and STN terms are plotted in Figs. 6a-d, respectively, for the control experiment (thick black line), as well as its anomaly in the NA (blue line) and GS (red line) experiments. The total atmospheric transport anomaly is southward from $40^{\circ} \mathrm{S}$ to $60^{\circ} \mathrm{N}$. In the tropics, this energy is carried by the crossequatorial Hadley cell (Fig. 6a). The subtropical Hadley cell boundaries, measured by the latitude of zero MMC transport, also shift northward in both hemispheres.

In the midlatitudes, the heat transport by the Ferrel cells (MMC) and the transient eddies (TRS) show opposite dipolar anomalies (Figs. 6a,b) that both correspond to a shift of the mean state to the north. In the Southern Hemisphere, the eddies dominate, and the net atmospheric energy transport is slightly northward. In the Northern Hemisphere, an additional southward energy transport by the stationary waves (Fig. 6c) leads to near compensation. Finally, the $Q$-flux anomaly is communicated to the tropics by the way of an anomalous southward atmospheric heat transport in the vicinity of $30^{\circ} \mathrm{N}$. Poleward of these latitudes, the net anomalous atmospheric energy transport is close to zero; there is, however, a northward net transport of moisture (not shown), leading to the precipitation increase around $60^{\circ} \mathrm{N}$ (Fig. 2a).

This study confirms an important result that previous studies have generally only speculated: the transient eddies are responsible for transporting midlatitude $Q$-flux anomalies into the tropics. Indeed, in the Northern Hemisphere, the poleward transient eddy fluxes are shifted to the north, as is clearly seen in Fig. $6 \mathrm{~b}$ in the $30^{\circ}-45^{\circ} \mathrm{N}$ latitude band, which results in anomalous southward transport in the subtropics. To check the spatial distribution of these eddy fluxes, the anomalous meridional heat fluxes by transient eddies $\left(v^{\prime} T^{\prime}, 2-8\right.$ days time filtered from the daily model output) at $850 \mathrm{hPa}$ is shown in Fig. 7. There is a clear northward shift of transient fluxes in the storm tracks regions of both the Atlantic and Pacific basins, with comparable amplitudes, with less signal over the continents.

In a series of idealized aquaplanet simulations, Kang et al. (2014) have shown that a zonally asymmetric $Q$-flux forcing, when confined in the extratropics, is quickly homogenized by midlatitude westerlies and extratropical eddies before propagating into the tropics. This mechanism seems also at play here: while the $Q$-flux forcing is concentrated in the North Atlantic between $30^{\circ}$ and $60^{\circ} \mathrm{N}$, the surface temperature anomaly (Fig. 9e) is zonally homogenized. The vertical structure is shown by a vertical longitude-pressure section of the temperature anomaly averaged in latitude over $30^{\circ}-60^{\circ} \mathrm{N}$ (Fig. 8). The temperature response is most strongly baroclinic over the prescribed $Q$-flux anomaly, as expected. At other longitudes, the response is more barotropic: the surface maximum is less marked and the warming expands from the surface to the upper troposphere. The zonal asymmetries, over the Pacific Ocean for example, can be traced to large-scale circulation changes (not shown) such as a Pacific-North American (PNA)-like response in the Pacific, and in the Atlantic a ridge downstream of the heating anomaly, consistent with Hoskins and Karoly (1981).

\section{Radiative response}

In addition to energy transport in the atmosphere, anomalous surface heat fluxes may also be compensated 
(a) MMC

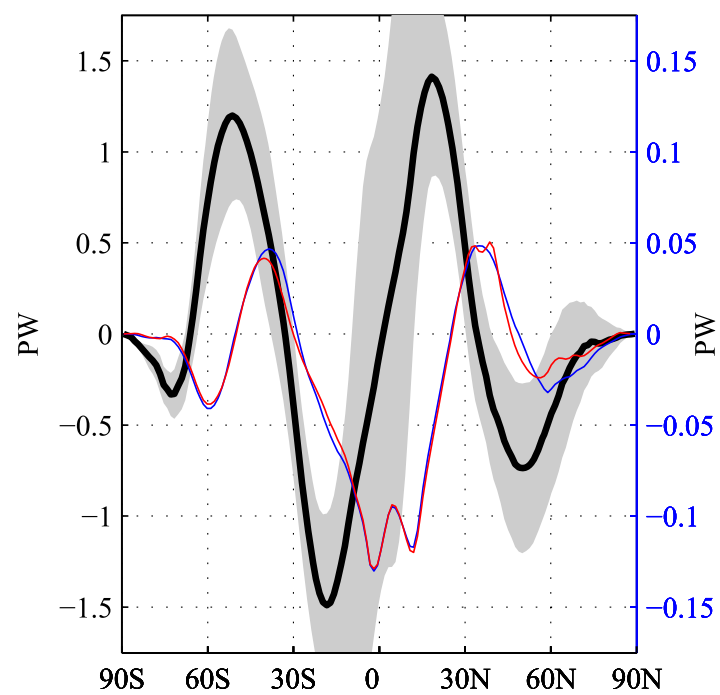

(b) TRS

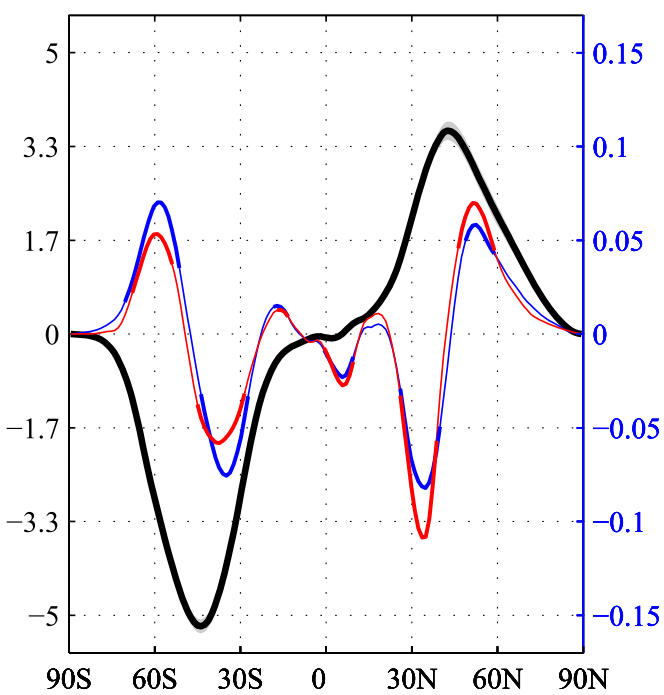

(c) STN

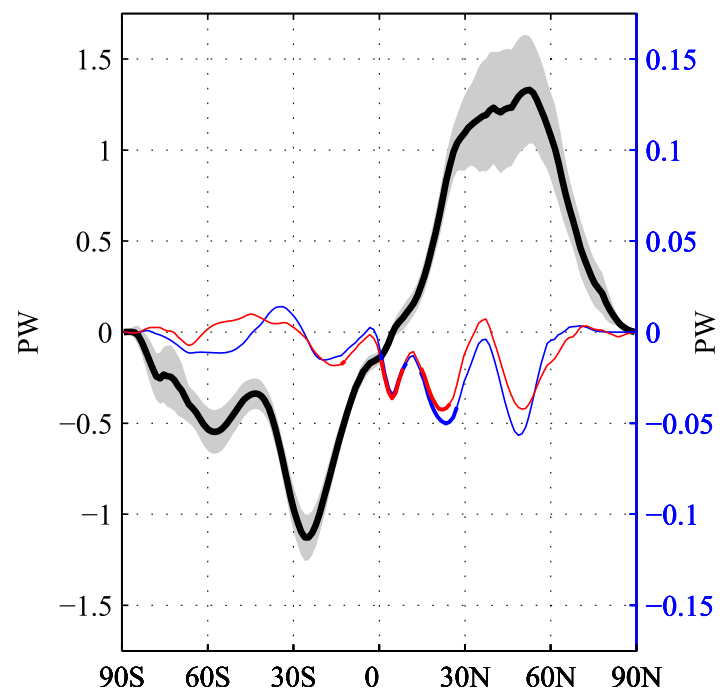

(d) Total

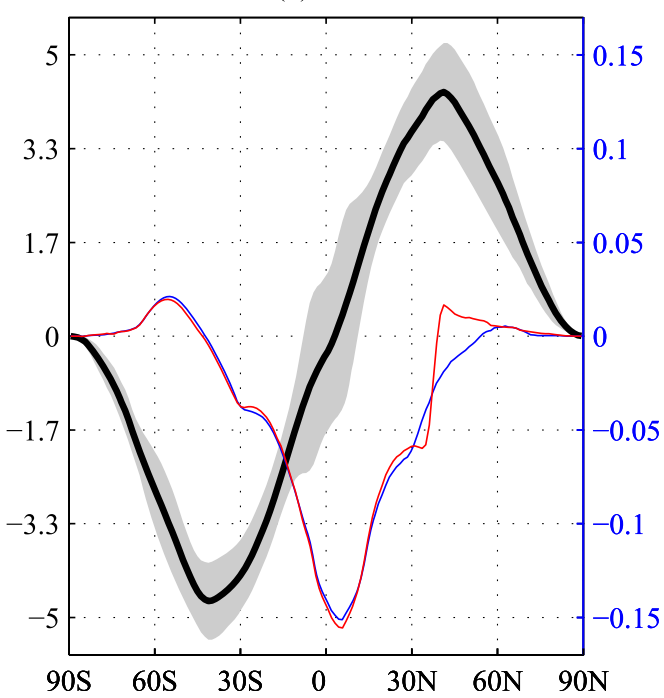

FIG. 6. Atmospheric transport of the mean static energy MSE and its three components (a) MMC, (b) TRS, and (c) STN, and (d) total MSE. The zonal mean of the control experiment is in thick black, with values on the left ordinate, while the anomalies are in light colors - with the NA experiment in blue and the GS in red-and the corresponding values are on the right ordinate. The gray-shaded strip represents the error bar of the zonal-mean climatology. For the anomalies, differences that are statistically significant at the $95 \%$ confidence level, according to a two-sided $t$ test, are drawn as a thicker line.

locally by changes in radiative fluxes at the TOA, which are shown in Fig. 9a (note that TOA outgoing values are negative). We can first note again that this response is very similar between the GS and NA cases outside of the North Atlantic (Fig. 9b). These total anomalies mask, however, a different behavior in clear and cloudy conditions. As shown in Fig. 5, the response when clear-sky conditions prevail would indeed compensate a large part of the oceanic forcing (in terms on implied energy transport), while cloud changes strongly reinforce it, especially in the northern midlatitudes. So, we now study separately these two radiative responses.

\section{a. Clear-sky response}

The two-dimensional response of clear-sky TOA fluxes in the NA experiment is shown in Fig. 9c, its zonal 


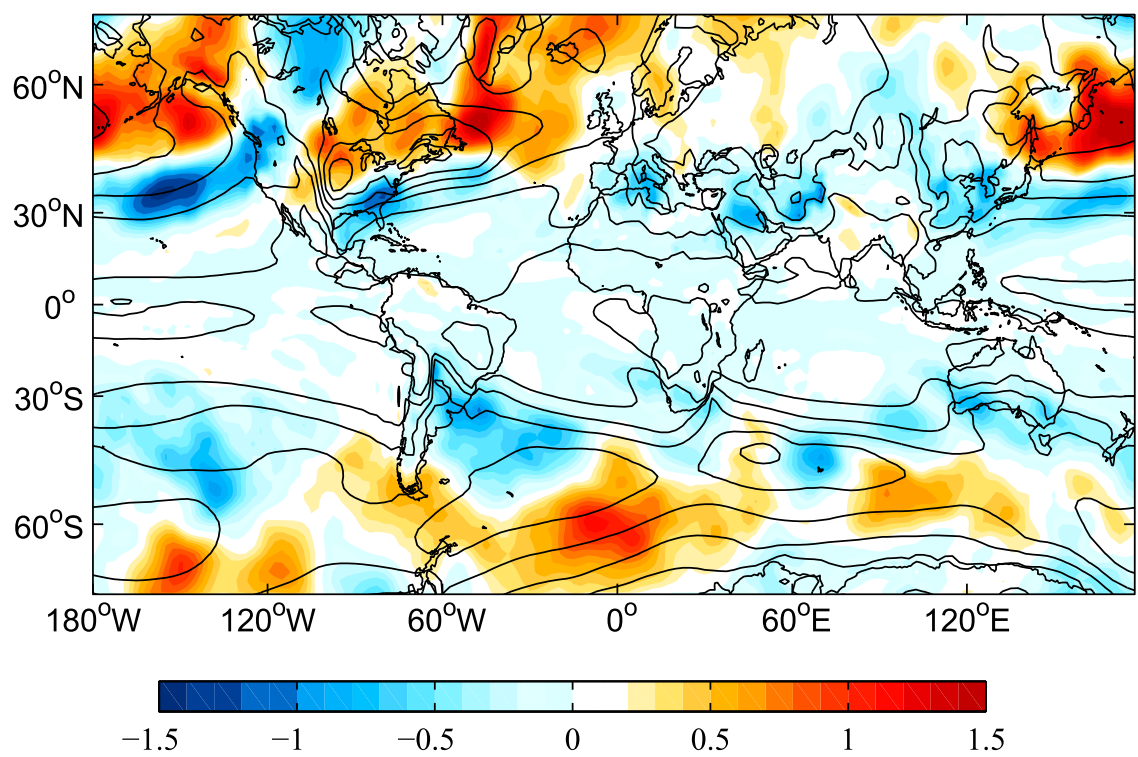

FIG. 7. Meridional heat flux $v^{\prime} T^{\prime}$ by transient eddies (2-8 days filtered) at $850 \mathrm{hPa}\left(\mathrm{K} \mathrm{m} \mathrm{s}^{-1}\right)$ : anomalies vs control in the NA experiment (color) and mean (contours).

average in Fig. 10a. Two distinct types of behavior appear in the tropics versus the midlatitudes; they are separated by a boundary around $30^{\circ}$.

In the midlatitudes, the clear-sky fluxes tend to oppose the $Q$-flux anomalies in the zonal mean. To interpret this behavior, we can note that the midlatitudes CS fluxes match very well the map of surface temperature changes (Fig. 9e): surface warming leads to increased outgoing longwave radiation and vice versa, damping the surface anomaly. As seen in section 4, both the temperature changes and TOA fluxes are spread over all longitudes, even in the Northern Hemisphere. These surface temperature changes are tied to moisture changes, especially over the oceans, as shown by the precipitable water changes (Fig. 9f). A warmer temperature leads to increased moisture, which would tend to decrease the outgoing radiation through an increased greenhouse effect. This is, however, clearly not enough to overcome the temperature change.

The dominant mechanism is different in the tropics, where the clear-sky response closely follows the pattern of precipitable water changes (Fig. 9f), with decreased outgoing longwave radiation in wetter regions, and an increase in drier ones. Here also, "temperature effect" and "water vapor effect" compete; however, moisture changes are here linked with shifts of the ITCZ and wet regions of the tropics (cf. Figs. 9f and 3) and are thus much larger than in the midlatitudes. The water vapor effect thus dominates, with the troposphere becoming more humid in regions with increased convective activity (Fig. 9f), implying a decrease of outgoing longwave radiation. A northward shift of the ITCZ therefore leads to a dipole in CS TOA radiation, with less energy lost in the Northern Hemisphere. This dipole in emitted longwave radiation then implies a southward energy transport, visible in the CS zonal mean (Fig. 10a), which amplifies locally the ITCZ shift and the amplitude of precipitation changes. Although some feedback studies have already found a net positive feedback in the tropics (Zelinka and Hartmann 2012), the novelty of our analysis is to link it explicitly to clear-sky processes.

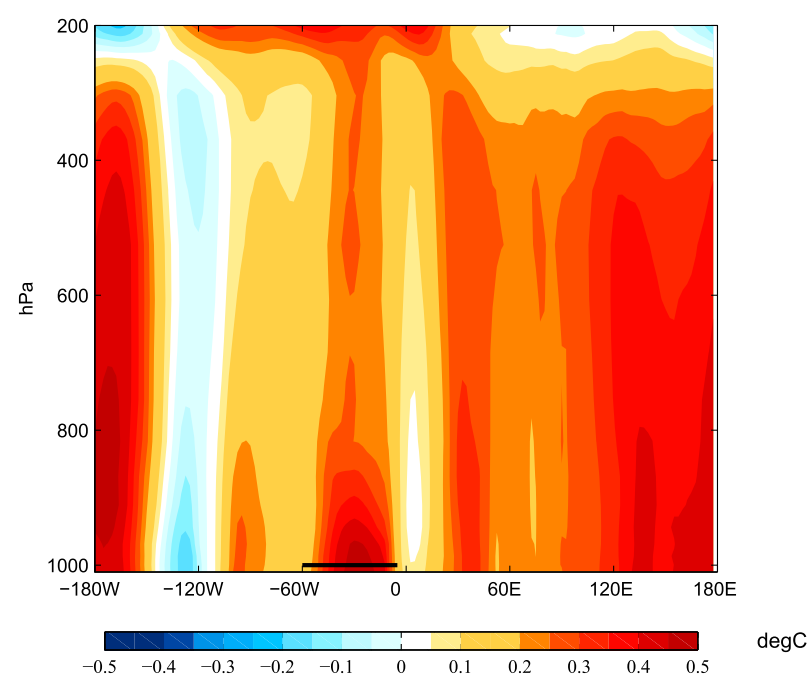

FIG. 8. Vertical cross section (longitude-pressure) of the temperature anomaly averaged in latitude over $30^{\circ}-60^{\circ} \mathrm{N}$ in the NA experiment $\left({ }^{\circ} \mathrm{C}\right)$. The black line shows the location of the added North Atlantic $Q$ flux in the NA experiment. 
(a) total TOA (NA-CTRL)

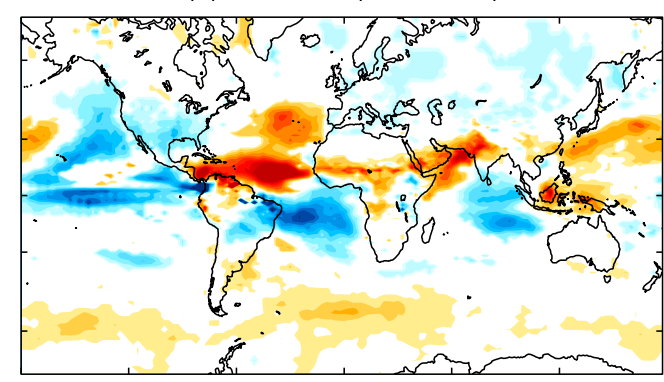

(c) "CS" TOA (NA-CTRL)

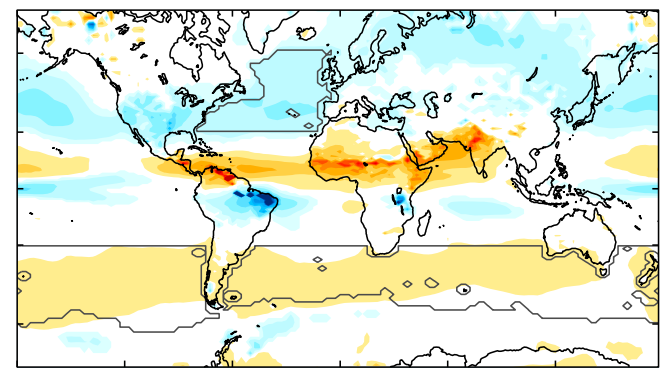

(e) TSOL (NA-CTRL)

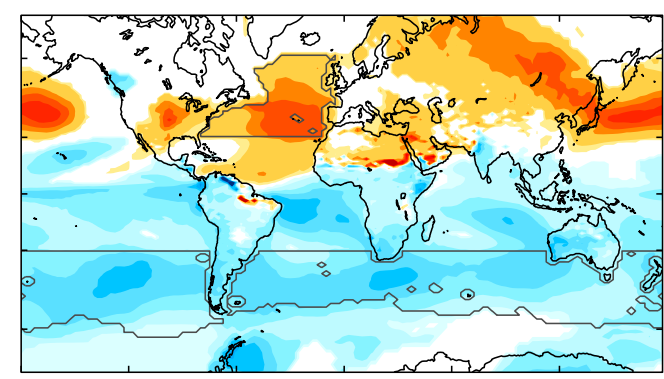

(b) total TOA (NA-GS)

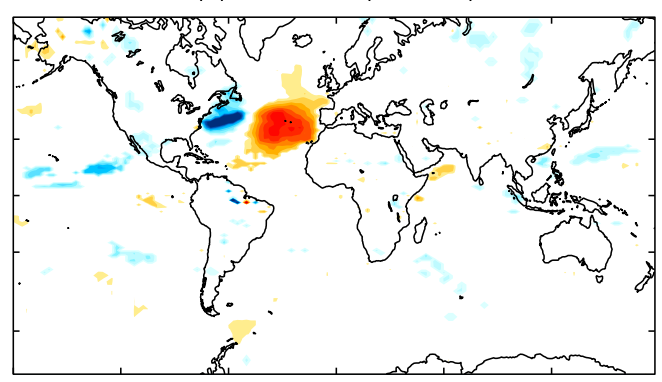

(d) "CRE" TOA (NA-CTRL)

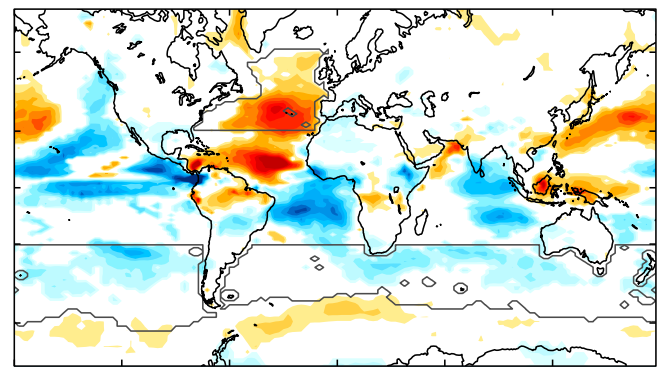

(f) precipitable water (NA-CTRL)

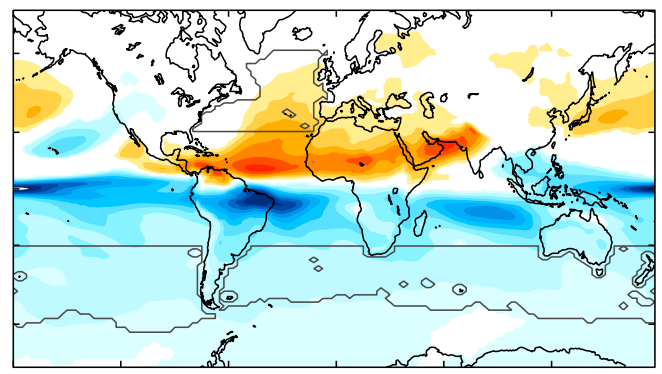

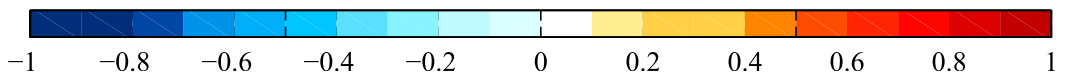

FIG. 9. TOA radiation $\left(\mathrm{W} \mathrm{m}^{-2}\right)$ : (a) anomaly vs control in the NA experiment and (b) difference between the NA and GS experiments. The NA anomaly shown in (a) is decomposed into (c) CS radiation and (d) CRE. (e) Surface temperature and (f) precipitable water anomaly vs control in the NA experiment. Differences that are not statistically significant at the $95 \%$ confidence level, according to a two-sided $t$ test, are in white. Contours of the $Q$-flux anomaly in the NA experiment are drawn in gray in the latter four panels. Color bar scale: $5 \mathrm{~W} \mathrm{~m}^{-2}$ in (a)-(d), $1^{\circ} \mathrm{C}$ in (e), and $2.5 \mathrm{~kg} \mathrm{~m}^{-2}$ in (f). TOA outgoing values are negative.

\section{b. Cloud radiative effects}

The two-dimensional picture of the cloud radiative effect anomaly in the NA simulation is plotted in Fig. 9d. Compared with the clear-sky case, its structure is more complex especially in the tropics, with little correlation with precipitation changes. It is thus useful to decompose the cloud response into its longwave and shortwave components, as well as changes in low (below $850 \mathrm{hPa}$ ) and high-cloud cover (Fig. 11). Midlevel cloud cover change will not be considered because it is negligible compared to low- and high-cloud cover changes.
High clouds (Fig. 11c) explain most of the longwave signal (Fig. 11a) as well as some of the shortwave one. They can be either thin cirrus clouds or thick clouds associated with deep convection. In the latter case, there is a lot of compensation between the shortwave and longwave components, as already noted by Zhang et al. (2010) in their study. Here it can be seen by comparing, for example, Figs. 11a,b over the tropical and subtropical continents: there is little signal left in the total CRE of Fig. 9d.

Changes in low-cloud cover (Fig. 11d) have instead a strong shortwave signature because of their albedo, 
(a) CS

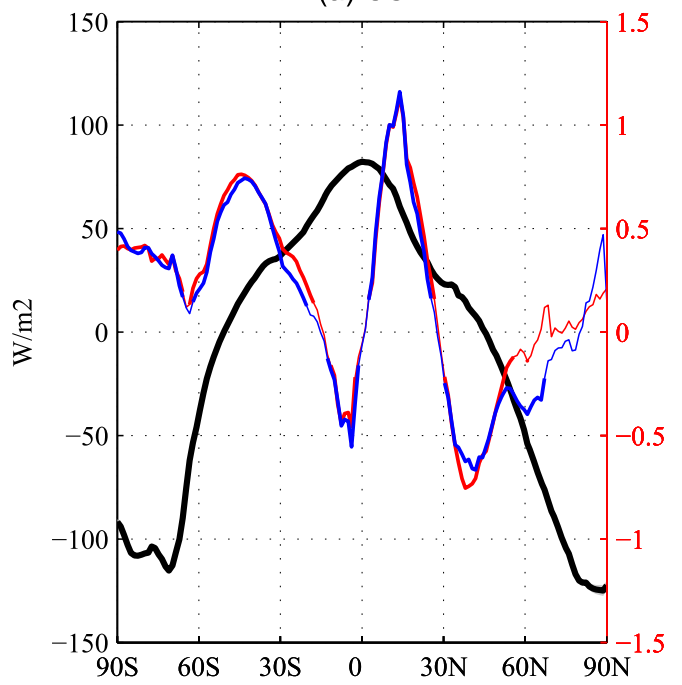

(b) CRE

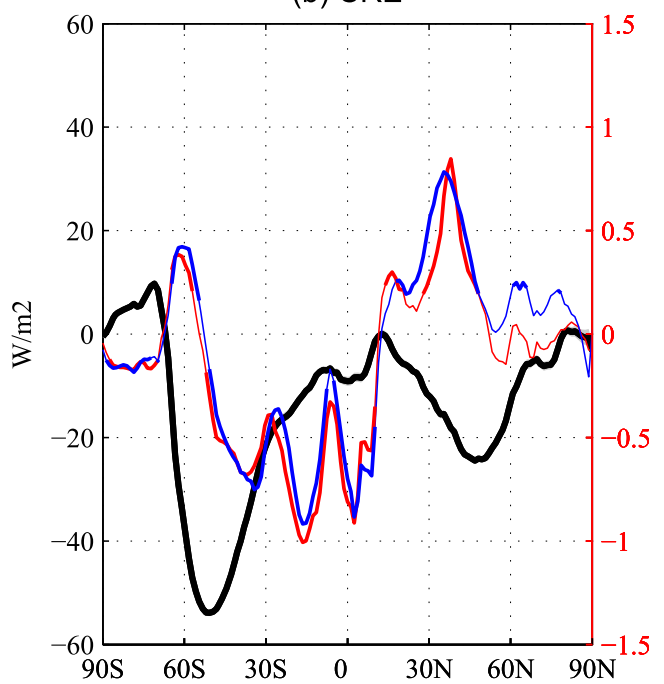

FIG. 10. Zonally averaged TOA fluxes $\left(\mathrm{W} \mathrm{m}^{-2}\right.$ ). (a) CS net radiation and (b) CRE. Control experiment (black, left ordinate) and anomaly in the NA (blue) and GS (red) experiments (right ordinate). Differences that are statistically significant at the $95 \%$ confidence level, according to a two-sided $t$ test, are drawn as a thicker line. TOA outgoing values are negative.

which is not compensated in the longwave domain. The response tends to follow changes in low-level stability, with cloud cover decreasing over a warmer surface, letting in more incoming radiation. This positive shortwave and net cloud feedback observed between $20^{\circ}$ and $50^{\circ}$ is a fairly robust response to SST increase in climate models, despite large uncertainties in the magnitude of the response (Zelinka and Hartmann 2012, their Figs. 3a, 4b). Is it only active over the oceans; there is no change in cloud cover over Siberia, for example, despite a strong surface warming.

This direct thermodynamic response above can be significantly modified by circulation changes, in particular by the northward shift of the jets and of the associated clouds and rainfall. Over the Southern Ocean, for example, the CRE has a meridional-dipole structure, with more radiation being absorbed south of $60^{\circ} \mathrm{S}$ and less in the subtropics. More local effects also play a role, as is the case in the North Pacific, where the CRE's spatial pattern recalls that of the Pacific decadal oscillation (PDO). Because of these circulation effects, the latitudes of strong positive feedback by CRE anomalies do not match perfectly-when inspected in the zonalmean picture of Fig. 10b-the initial forcing regions, whose boundaries are plotted in gray in Figs. 9c,d.

In summary, the large compensation of high-cloud changes means that the net CRE pattern (Fig. 9d) closely follows changes in low-cloud cover (Fig. 11d), which are not closely related to precipitation changes. This cloud radiative effect leads to a net cooling in the tropics and Southern Hemisphere, and a net warming in the northern midlatitudes (Fig. 10b), yielding an overall positive feedback on the imposed $Q$-flux forcing.

\section{Concluding remarks}

\section{a. Discussion}

\section{1) OCEAN DYNAMICS}

In this study, the use of a slab ocean allowed us to specify in a controlled way the surface heat flux anomalies associated with changes in oceanic heat transport, and to focus on the atmospheric response. In reality, active ocean dynamics could modify this response in a number of ways.

On shorter time scales, changes in ocean heat storage could delay and even dominate the response to heat transport anomalies. The oceanic circulation can also change in response to the initial forcing and feed back in turn on the meridional heat transport: the gyres, eddies, and AMOC can adjust to the anomalies in density and winds (Chen and Ghil 1995), or just passively advect the temperature anomalies. The change in tropical surface winds is expected to lead to an oceanic overturning circulation in the same sense as the Hadley cell anomaly, and thus leading to an additional energy transport by the ocean that may replace part of the atmospheric one. Thus, interactive ocean dynamics would be expected to result in the ITCZ shift being smaller in a coupled setting with ocean dynamics than that reported here. This was found by Cheng et al. (2007), where the ocean's baroclinic adjustment and dynamical response to the 
(a) LW "CRE" (NA-CTRL)

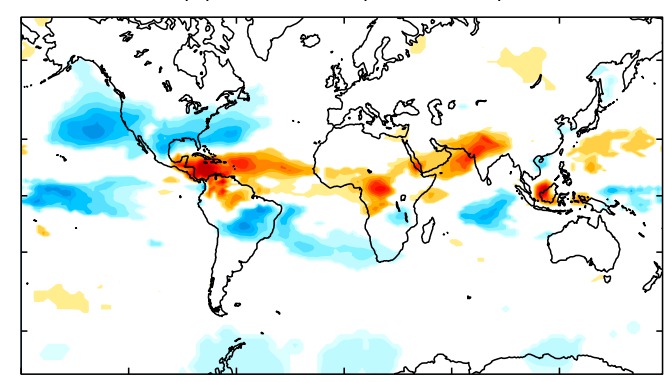

(c) high-cloud (NA-CTRL)

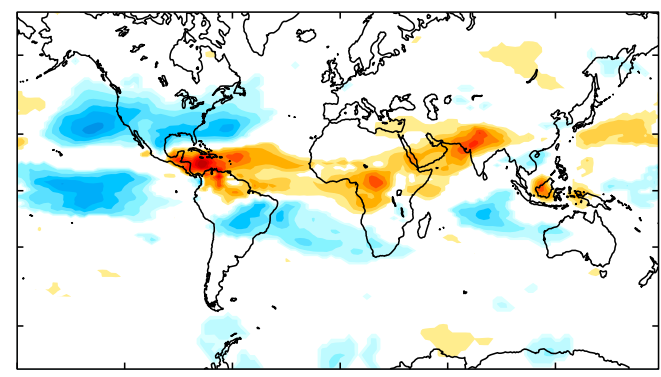

(b) SW "CRE" (NA-CRTL)

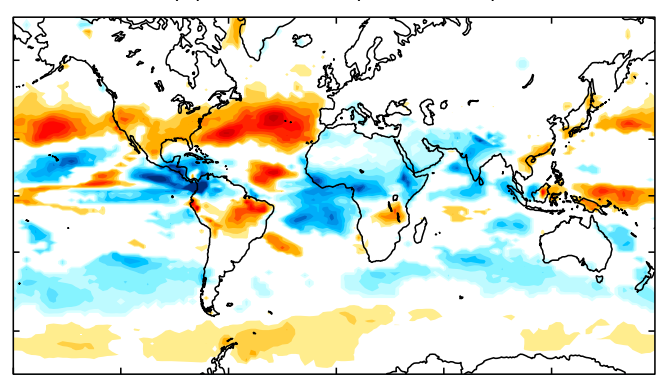

(d) low-cloud (NA-CTRL)

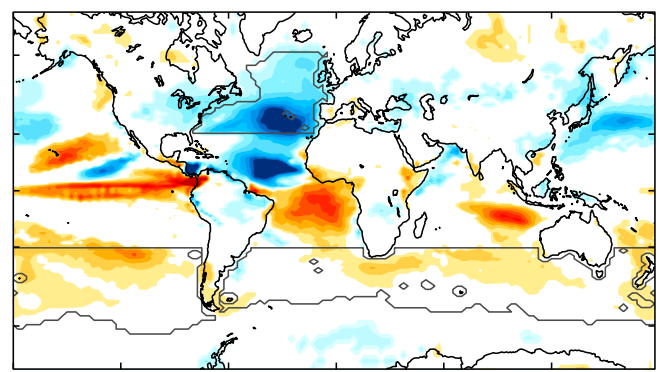

$\begin{array}{llll} & & & \\ 0.4 & 0.6 & 0.8\end{array}$

FIG. 11. Repartition of the CRE anomaly in the NA experiment between (a) longwave and (b) shortwave components. (c) High-cloud and (d) low-cloud amount anomalies (\%). Differences that are not statistically significant at the $95 \%$ confidence level, according to a two-sided $t$ test, are in white. Contours of the $Q$-flux anomaly in the NA experiment are drawn in gray in the last panel. Color bar scale: $5 \mathrm{~W} \mathrm{~m}^{-2}$ in (a) and (b), and $0.05 \%$ in (c) and (d).

changed winds damped the WES influence in the North Atlantic.

Finally, local ocean dynamics can modify the distant response to high-latitude interhemispheric thermal forcing. In a twin experiment with a full versus slab ocean model coupled to the same atmospheric GCM, Zhang and Delworth (2005) demonstrated that in the tropical Pacific, ocean-atmosphere dynamical processesoceanic upwelling/downwelling in response to surface wind anomalies-did amplify the local response to their Atlantic high-latitude forcing. Wen et al. (2011), using the CCM3 atmospheric model coupled to a 2.5-layer reduced-gravity ocean (RGO) model, showed the role of local coupling with the Gulf of Guinea ocean temperature in the precipitation changes over West Africa. An influence of the AMOC on the North Pacific variability was also found in several studies, with different suggested mechanisms: either through midlatitude atmospheric teleconnections (Zhang and Delworth 2007) or through an atmospheric bridge via the tropical Atlantic and the tropical Pacific (Okumura et al. 2009). In both theories, the response of the Aleutian low is reinforced by ocean dynamics - via gyre adjustment and advection-and by positive air-sea feedback over the North Pacific. A dynamic ocean might, however, not be absolutely necessary for a strong impact on the PDO, which is obtained also in the present study.

\section{2) Cloud feedBacks}

A number of previous studies already highlighted the crucial role of low-cloud effect in amplifying the interhemispheric atmospheric heat transport and, therefore, the ITCZ shift (Kang et al. 2008, 2009; Zhang et al. 2010; Seo et al. 2014). Such low-cloud cover changes, however, are highly model dependent; they are responsible for much of the overall spread in cloud radiative effects and climate sensitivities among GCMs. In Fig. 1b in Voigt et al. (2014), model differences in representing the CRE for tropical clouds is highlighted. The LMDZ5A-MR-MR for medium resolution-configuration used here presents a sensitivity close to the observations. This high climate sensitivity is due to a strong low-cloud radiative effect, also observed in extratropical regions (Hourdin et al. 2013; Sherwood et al. 2014). In our experiments, the low-cloud radiative effect does, indeed, dominate the cloud response, whereas the effects of high clouds are weaker. 
In addition to these extratropical cloud feedbacks, we also obtained a positive feedback on cross-equatorial heat transport and ITCZ shifts internal to the tropics. This feedback is due to the clear-sky longwave radiation: the ITCZ region presents a maximum of relative humidity, especially in the free troposphere, which leads to a local minimum in outgoing longwave radiation. A shift of the ITCZ leads, therefore, to an opposite dipole in radiative heat loss by the atmosphere.

\section{b. Conclusions}

We studied here the impacts of prescribed anomalies of northward oceanic heat transport-with extratropical warming in the North Atlantic and cooling in the Southern Ocean-in an atmospheric, IPCC-class GCM coupled to a slab ocean. Compared to previous, idealized studies, we used a realistic setting, both in terms of geography and in the amplitude of the imposed anomalies, which are in the range of natural, decade-todecade variability as well as of typical model biases.

Consistent with previous studies, we find a response of tropical precipitation such as the ITCZ shifts toward the warmer hemisphere. Another important result is that the global climate response is nearly insensitive to the longitudinal distribution of the heating. Furthermore, we showed that the cloud response acts as a large positive feedback on the oceanic forcing, mainly because of the lowcloud-induced shortwave anomalies in the extratropics.

Finally, the role of transient eddies in propagating signal to the tropics has been highlighted in this study. Indeed, in the midlatitudes, we find a systematic northward shifts of the jets, as well as of the associated Ferrel cells, storm tracks, and precipitation bands. While previous literature has speculated that the extratropical $Q$ flux may impact the tropics by the way of the transient eddy fluxes (Deremble et al. 2012), it is explicitly demonstrated here.

Both eddy heat transport and cloud feedbacks are split between the Pacific and Atlantic basins, despite an initial forcing confined to the Atlantic. There is little signal of either over the continents, however, despite similar local temperature changes. This highlights the need to check results from idealized models in more realistic settings. These conclusions will now need to be further tested in atmospheric GCMs with a higher horizontal resolution and with active coupling to a dynamic ocean GCM.

Acknowledgments. We thank Aaron Donohoe, two anonymous reviewers, and Editor John Chiang for their thoughtful comments. Discussions with Sandrine Bony and Isaac Held during the project were stimulating and helpful. We acknowledge financial support from Agence Nationale de la Recherche under the reference ANR 2011 Blanc SIMI 5-6 014 01. This work was granted access to the HPC resources of CCRT/CINES/IDRIS under the allocation 2011-016852 made by Grand Equipement National de Calcul Intensif (GENCI).

\section{REFERENCES}

Adler, R. F., and Coauthors, 2003: The Version-2 Global Precipitation Climatology Project (GPCP) monthly precipitation analysis (1979-present). J. Hydrometeor., 4, 1147-1167, doi:10.1175/1525-7541(2003)004<1147:TVGPCP > 2.0.CO;2.

Baringer, M., and Coauthors, 2013: Meridional overturning circulation and heat transport observations in the Atlantic Ocean [in "State of the Climate in 2012"]. Bull. Amer. Meteor. Soc., 94 (8), S65-S68.

Brachet, S., F. Codron, Y. Feliks, M. Ghil, H. Le Treut, and E. Simonnet, 2012: Atmospheric circulations induced by a midlatitude SST front: A GCM study. J. Climate, 25, 18471853, doi:10.1175/JCLI-D-11-00329.1.

Broccoli, A. J., K. A. Dahl, and R. J. Stouffer, 2006: Response of the ITCZ to Northern Hemisphere cooling. Geophys. Res. Lett., 33, L01702, doi:10.1029/2005GL024546.

Ceppi, P., Y.-T. Hwang, X. Liu, D. M. W. Frierson, and D. L. Hartmann, 2013: The relationship between the ITCZ and the Southern Hemispheric eddy-driven jet. J. Geophys. Res. Atmos., 118, 5136-5146, doi:10.1002/jgrd.50461.

Chen, C.-T., and V. Ramaswamy, 1996: Sensitivity of simulated global climate to perturbations in low cloud microphysical properties. Part II: Spatially localized perturbations. J. Climate, 9, 2788-2801, doi:10.1175/1520-0442(1996)009<2788: SOSGCT $>2.0 . \mathrm{CO} ; 2$.

Chen, F., and M. Ghil, 1995: Interdecadal variability of the thermohaline circulation and high-latitude surface fluxes. J. Phys. Oceanogr., 25, 2547-2568, doi:10.1175/1520-0485(1995)025<2547: IVOTTC $>2.0 . \mathrm{CO} ; 2$.

Cheng, W., C. M. Bitz, and J. C. H. Chiang, 2007: Adjustment of the global climate to an abrupt slowdown of the Atlantic meridional overturning circulation. Ocean Circulation: Mechanisms and Impacts-Past and Future Changes of Meridional Overturning, Geophys. Monogr., Vol. 173, Amer. Geophys. Union, 295-313.

Chiang, J. C. H., and C. M. Bitz, 2005: Influence of high latitude ice cover on the marine intertropical convergence zone. Climate Dyn., 25, 477-496, doi:10.1007/s00382-005-0040-5.

Deremble, B., G. Lapeyre, and M. Ghil, 2012: Atmospheric dynamics triggered by an oceanic SST front in a moist quasigeostrophic model. J. Atmos. Sci., 69, 1617-1632, doi:10.1175/ JAS-D-11-0288.1.

Donohoe, A., J. Marshall, D. Ferreira, and D. McGee, 2013: The relationship between ITCZ location and cross-equatorial atmospheric heat transport: From the seasonal cycle to the Last Glacial Maximum. J. Climate, 26, 3597-3618, doi:10.1175/ JCLI-D-12-00467.1.

,,--- K. Armour, and D. McGee, 2014: The interannual variability of tropical precipitation and interhemispheric energy transport. J. Climate, 27, 3377-3392, doi:10.1175/JCLI-D-13-00499.1.

Feliks, Y., M. Ghil, and E. Simonnet, 2007: Low-frequency variability in the midlatitude baroclinic atmosphere induced by an oceanic thermal front. J. Atmos. Sci., 64, 97-116, doi:10.1175/ JAS3780.1.

Frierson, D. M., and Y.-T. Hwang, 2012: Extratropical influence on ITCZ shifts in slab ocean simulations of global warming. J. Climate, 25, 720-733, doi:10.1175/JCLI-D-11-00116.1. 
and Coauthors, 2013: Contribution of ocean overturning circulation to tropical rainfall peak in the Northern Hemisphere. Nat. Geosci., 6, 940-944, doi:10.1038/NGEO1987.

Fučkar, N. S., S.-P. Xie, R. Farneti, E. A. Maroon, and D. M. W. Frierson, 2013: Influence of the extratropical ocean circulation on the intertropical convergence zone in an idealized coupled general circulation model. J. Climate, 26, 4612-4629, doi:10.1175/JCLI-D-12-00294.1.

Hoskins, B. J., and D. J. Karoly, 1981: The steady linear response of a spherical atmosphere to thermal and orographic forcing. $J$. Atmos. Sci., 38, 1179-1196, doi:10.1175/1520-0469(1981)038<1179: TSLROA $>2.0 . \mathrm{CO} ; 2$.

Hourdin, F., and Coauthors, 2013: Impact of the LMDZ atmospheric grid configuration on the climate and sensitivity of the IPSL-CM5A coupled model. Climate Dyn., 40, 2167-2192, doi:10.1007/s00382-012-1411-3.

Hwang, Y., and D. M. Frierson, 2013: Link between the doubleintertropical convergence zone problem and cloud biases over the Southern Ocean. Proc. Natl. Acad. Sci. USA, 110, 49354940, doi:10.1073/pnas.1213302110.

Isemer, H.-J., and L. Hasse, 1987: The Bunker Climatic Atlas of the North Atlantic. Vol. 2, Air-Sea Interactions, Springer-Verlag, 252 pp.

Kang, S. M., I. M. Held, D. M. W. Frierson, and M. Zhao, 2008: The response of the ITCZ to extratropical thermal forcing: Idealized slab-ocean experiments with a GCM. J. Climate, 21, 35213532, doi:10.1175/2007JCLI2146.1.

—, D. M. W. Frierson, and I. M. Held, 2009: The tropical response to extratropical thermal forcing in an idealized GCM: The importance of radiative feedbacks and convective parameterization. J. Atmos. Sci., 66, 2812-2827, doi:10.1175/ 2009JAS2924.1.

_ I. M. Held, and S.-P. Xie, 2014: Contrasting the tropical responses to zonally asymmetric extratropical and tropical thermal forcing. Climate Dyn., 42, 2033-2043, doi:10.1007/s00382-013-1863-0.

Lorenz, E. N., 1967: The Nature and Theory of the General Circulation of the Atmosphere. World Meteorological Organization, $161 \mathrm{pp}$.

Mahajan, S., R. Saravanan, and P. Chang, 2011: The role of the wind-evaporation-sea surface temperature (WES) feedback as a thermodynamic pathway for the equatorward propagation of high-latitude sea ice-induced cold anomalies. J. Climate, 24, 1350-1361, doi:10.1175/2010JCLI3455.1.

_ - K. J. Evans, J. J. Hack, and J. E. Truesdale, 2013: Linearity of climate response to increases in black carbon aerosols. J. Climate, 26, 8223-8237, doi:10.1175/JCLI-D-12-00715.1.

Marshall, J., A. Donohoe, D. Ferreira, and D. McGee, 2014: The ocean's role in setting the mean position of the inter-tropical convergence zone. Climate Dyn., 42, 1967-1979, doi:10.1007/ s00382-013-1767-z.
Ming, Y., and V. Ramaswamy, 2009: Nonlinear climate and hydrological responses to aerosol effects. J. Climate, 22, 13291339, doi:10.1175/2008JCLI2362.1.

Minobe, S., A. Kuwano-Yoshida, N. Komori, S. P. Xie, and R. J. Small, 2008: Influence of the Gulf Stream on the troposphere. Nature, 452, 206-209, doi:10.1038/nature06690.

Okumura, Y. M., C. Deser, A. Hu, A. Timmermann, and S.-P. Xie, 2009: North Pacific climate response to freshwater forcing in the subarctic North Atlantic: Oceanic and atmospheric pathways. J. Climate, 22, 1424-1445, doi:10.1175/2008JCLI2511.1.

Seo, J., S. M. Kang, and D. M. W. Frierson, 2014: Sensitivity of intertropical convergence zone movement to the latitudinal position of thermal forcing. J. Climate, 27, 3035-3042, doi:10.1175/JCLI-D-13-00691.1.

Sherwood, S. C., S. Bony, and J.-L. Dufresnes, 2014: Spread in model climate sensitivity traced to atmospheric convective mixing. Nature, 505, 37-42, doi:10.1038/nature12829.

Voigt, A., S. Bony, J.-L. Dufresne, and B. Stevens, 2014: The radiative impact of clouds on the shift of the intertropical convergence zone. Geophys. Res. Lett., 41, 4308-4315, doi:10.1002/2014GL060354.

Wen, C., P. Chang, and R. Saravanan, 2011: Effect of Atlantic meridional overturning circulation on tropical Atlantic variability: A regional coupled model study. J. Climate, 24, 33233343, doi:10.1175/2011JCLI3845.1.

Willison, J., W. A. Robinson, and G. M. Lackmann, 2013: The importance of resolving mesoscale latent heating in the North Atlantic storm track. J. Atmos. Sci., 70, 2234-2250, doi:10.1175/ JAS-D-12-0226.1.

Yoshimori, M., and A. J. Broccoli, 2008: Equilibrium response of an atmosphere-mixed layer ocean model to different radiative forcing agents: Global and zonal mean response. J. Climate, 21, 4399-4423, doi:10.1175/2008JCLI2172.1.

Zelinka, M. D., and D. L. Hartmann, 2012: Climate feedbacks and their implications for poleward energy flux changes in a warming climate. J. Climate, 25, 608-624, doi:10.1175/ JCLI-D-11-00096.1.

Zhang, R., and T. L. Delworth, 2005: Simulated tropical response to a substantial weakening of the Atlantic thermohaline circulation. J. Climate, 18, 1853-1860, doi:10.1175/JCLI3460.1.

— and _ 2007: Impact of the Atlantic multidecadal oscillation on North Pacific climate variability. Geophys. Res. Lett., 34, L23708, doi:10.1029/2007GL031601.

_ - S. M. Kang, and I. M. Held, 2010: Sensitivity of climate change induced by the weakening of the Atlantic meridional overturning circulation to cloud feedback. J. Climate, 23, 378389, doi:10.1175/2009JCLI3118.1.

Zheng, Y., and B. S. Giese, 2009: Ocean heat transport in Simple Ocean Data Assimilation: Structure and mechanisms. J. Geophys. Res., 114, C11009, doi:10.1029/2008JC005190. 